brought about : first, by steady selection of such variations or mutations as may occur in the direction of such change; secondly, by transmission of modifications acquired by the rats in the course of training. It seems very improbable that selection can have played any appreciable part in producing the change of constitution here described; and still more improbable that selection can have been the main or the sole process. It begins to look to the writer as though Lamarckian transmission were a real process in nature; and he submits for criticism the proposition that, if continuance of the experiment, combining training with strongly adverse selection, should result in steadily increasing facility, the reality of Lamarckian transmission will have been demonstrated.

C. S. R.

[237] Maximum capacity and average achievement.-S. WyatT. Brit. Jour. of Psychol., 1930, xx, 251.

IT is suggested that the difference between maximum capacity recorded under the most favourable conditions and average achievement observed throughout a spell of work is a measure of the combined influence of factors which are detrimental to productive activity. A suitable measure of maximum capacity is the highest rate of working attained in a period of five minutes. This value is very consistent in the case of the same individual observed at corresponding times on different days. The application of this method to industrial procedure can be used to show $(a)$ individual susceptibility to similar conditions of work; $(b)$ the total effect of unfavourable factors in different industrial processes ; $(c)$ the approximate influence of particular factors responsible for reduced activity. When applied to the processes considered in this article, there is evidence to show that $(a)$ one worker may be almost twice as susceptible as another to unfavourable elements associated with the conditions of work. (b) The quicker workers tend to deviate more than the slower operatives from their respective high speeds. (c) An imperfect relation exists between maximum and average rates of working, yet when all the workers in a group are actuated by a powerful incentive the degree of imperfection may be very slight. $(d)$ The difference between maximum and average rates of working may vary from 12 to 38 per cent. in different processes. (e) A time-rate system of payment is much less effective than a piece-rate and may cause a reduction in output amounting to approximately 12 per cent.

C. S. R.

\title{
PSYCHOSES.
}

[238] Psychosis and encephalitis (Les encéphalites psychosiques; étude anatomo-clinique).-E. Toulouse, L. Marchand, and P. Schiff. L'Encéphale, 1929, xxiv, 413.

THE authors furnish a description of a series of cases of acute psychosis in which a condition of acute encephalitis has been found at autopsy. The clinical 
form of the psychosis has been variable, being, however, mainly confusional in type. On the pathological side no specific histological feature has characterised the conditions. From the clinical aspect little by way of neurological signs has been present. According to the opinion of the writers the deduction is legitimate that some cases of acute psychosis derive from acute encephalitis caused by different, and as yet unrecognised, pathogenic factors.

J. V.

[239] Brain changes in dementia praecox (Les lésions cérébrales dans la démence précoce).-D'Hollander, De GreefFF and Ch. Rouvray. Jour. de neurol. et de psychiat., 1929, xxix, 643.

DetaILed histological study of the brains in seven fatal cases of schizophrenia showed a striking similarity in the pathological picture. Changes occurred throughout the whole of the cerebrum, brain-stem and cerebellum. Of particular interest were the changes in the meninges, consisting in an intense hyperplasia with lymphocytic infiltrations and endothelial nodules. Vascular alterations were widespread and important; they included areas of hyperplasia shown as plaques of inflammatory angiomatosis on the cortex of the cerebrum and cerebellum, regressive modifications in the blood vessels, with miliary hæmorrhages and perivascular necroses. In addition to all these, the authors also noted alterations in nerve parenchyma and neuroglia as described by numerous other observers.

M. C.

Circulatory disorders and psychoses (Kreislaufstörungen und Psychosen). -W. Spielmeyer. Zeits.f.d.g. Neurol. u. Psychiat., 1930, cxxiii, 536.

The author commences his well-illustrated article with a description of the pathological changes in the brain associated with psychoses in the presence of vascular disorders. These include the effects of arteriosclerosis, as well as the occurrence of areas of cortical and subcortical degeneration of cells and fibres produced by local 'bleaching ' of the parenchyma apart from obvious vascular disease in their actual vicinity. He next points out the significance of anatomical change of this kind, vascular in type, without disease of vessel-wall or occlusion of lumen. Such alterations are to be found with greater or less readiness in a variety of psychotic states of diverse etiology. Illustrations are furnished of their occurrence in the psychoses of eclampsia, morphinism, pseudo-uræmia, epilepsy, cerebral arteriosclerosis, etc. Yet they are also traceable in other cases unaccompanied clinically by any psychotic manifestation.

The value of such changes from the standpoint of diagnosis is therefore very slight; it resides rather in the fact that disease-conditions which are 
fundamentally different both etiologically and clinically cause symptomcomplexes whose pathogeneses very closely resemble each other. This general thesis the author elaborates at considerable length.

S. A. K. W.

[241] The biological syndrome of melancholic conditions (Le syndrome biologique des états melancholiques).-R. TARgowla and A. LAMache. L'Encéphale, 1929, xxiv, 166.

THIs is a review of present knowledge in respect of the 'psychosomatic syndrome' of melancholia, and supplies details of a series of clinical investigations bearing on the neurosympathetic phenomena of that psychosis. The data are rather diverse and cannot be conveniently summarised in abstract. The authors show that the essential feature of this syndrome is inhibition of metabolic change. Neurosympathetic excitability is definitely reduced; endocrine function is defective. Circulatory equilibrium is profoundly modified. These and other disorders accompany the psychosis and disappear as the mental state improves.

[242] Temperament, conflict and psychosis in a stone-age population.C. G. Seligman. Brit. Jour. Med. Psychol., 1929, ix, 187.

Tre population studied, i.e., of that part of Papua known until a few years ago as British New Guinea, is admittedly of an excitable and extrovert disposition. In spite of this and the frequency of suicide, both impulsive and ceremonial, there is no evidence of the occurrence of mental derangement, other than brief outbursts of maniacal excitement, among natives who have not been associated with white civilization. Fatal instances of insanity are cited in which the immediate cause (as evidenced by the history and delusions) was financial responsibility in connections with Europeans. In other instances (non-fatal) the difficulty has been in the religious field. Of late years a series of religious cults has arisen. These are characterized by hysterical dissociation and mass contagion, and in all except one there is evidence of the important part plaved by the conflict between old and new religious ideas.

C. S. R.

[243] Mentism (Le mentisme).-G. Hedyer and A. Lamache. L'Encêphale, 1929 , xxiv, 325.

THE term ' mentism' is not found to any extent in English psychiatric literature. In that of French schools it has been taken to mean 'intellectual effervescence,' ' mental rumination and compulsive reverie,' a 'succession of ideas,' etc. The writer suggests it should be regarded as including the following three notions :

1. A vivid mental presentation, conscious, in the field of imagination. 
2. It cannot be called up voluntarily on the one hand, or suppressed by the same agency on the other.

3. It is invariably accompanied by mental disquiet and a state of anxiety.

A series of clinical illustrations from diverse psychopathic states are here recorded, and the admission is made that it may occur in subjects who are practically normal. Among the cases quoted is one of cerebral tumour in which the symptom disappeared after decompression. It is well recognised in an early stage of dementia præcox.

\section{J. V.}

\section{PSYCHOPATHOLOGY.}

[244] The sedimentation test and icterus index : a few observations on their uses in a mental hospital.-Helen S. E. Murray. Jour. of Ment. Sci., 1930, lxxvi, 85.

Tre sedimentation test is a sensitive indicator of biochemical changes in the entire organism. It is not a specific test for any one disease, but is found in all conditions in which there is accompanying tissue destruction. As in a leucocytosis, an increased sedimentatiou reaction always indicates morbidity, but does not localize it. The test is of practical aid in detecting many pathological conditions, especially in dealing with insane and uncooperative patients. It is helpful in determining the diagnosis and progress of both mental and physical diseases, though its use in psychiatric diagnosis is limited. It does not give marked deviations from the normal in functional disturbances of the nervous system, but is modified in the majority of diseases of the central nervous system. Abnormally rapid sedimentation is associated with organic disease, and may be taken to exclude a purely functional disorder such as neurasthenia. It is also useful in the case of a neurotic and complaining patient who may have developed some pathological condition. The technique of the test is simple ; it is helpful in determining the progress of mental and physical diseases in addition to the diagnosis and differential diagnosis of many pathological conditions, especially in dealing with the insane, and so is of sufficient practical and clinical value to deserve further attention in mental hospitals.

C. S. R.

[245] An investigation into the distribution of chlorine in the blood and urine in certain types of mental disorder.-Robert W. Armstrong. Jour. of Ment. Sci., 1929, lxxv, 644.

FollowING on the increased respiratory ventilation after waking in the morning, the normal person shows an increased output of chlorides in the urine. In the psychotic patients examined there is a varying degree of retention of chlorides over the same period associated with a varying degree of defect in respiratory regulation. In katatonic dementia præcox there appears to be a 